\title{
Life-Long Learning Know-How Transfer Centers for Flood Risk Assessment in Romania and Hungary
}

\author{
An EU-Cooperation-Project
}

\author{
Ioan David, Erika Beilicci, \\ Robert Beilicci, Camelia Stefanescu \\ „POLITECHNICA“ University of Timisoara \\ Department of Hydrotechnical Engineering \\ Timisoara, Romania \\ ioan.david@ct.upt.ro; ioan.david@gmx.net
}

\author{
Zsuzsanna Nagy \\ DHI a.s. \\ Prague, Czech Republic \\ Dana Stoian \\ Victor Babes University of Medicine and Pharmacy, \\ Timisoara, Romania
}

\begin{abstract}
The sector affected by surplus or scarcity of water requires proper understanding of river and landscape system behavior, what is possible to be done to prevent potential damages and losses need skilled professionals, who are familiar also with the newest IT based hydroinformatic tools and technological achievements to find the best possible solutions. An extensive programs of Water Authorities in Romania and in Hungary have been running to provide flood risk maps in all the main river basins including also those which across the both countries. The obtained results will be contribute to the better understanding and general prediction of flooding on the major river systems and assist the governments to act (in real time and space) in accordance with contingency planning based on flood risk management plans, moreover future development plans of regions and cities will get a proper guidance and platforms for future feasibility studies. However Flood Directive implementation has been ongoing in Romania and Hungary, 'bridging and direct trainings' for relevant sectors as it is planned in this project have not been provided and have not been planned for future in Romania and Hungary. Based on these needs in 2011 was initiated and organized an international cooperation project financed by the European Union with the theme: "Development of knowledge canters for life-long learning by involving of specialists and decision makers in flood risk management using advanced Hydroinformatic tools" [1]. In this paper we give a brief overview of the main objectives proposed, a description of the partners and some aspects of the activities developed in the project and some of the results obtained
\end{abstract}

Keywords - life-long learning, flood risk management, knowhow transfer

\section{INTRODUCTION}

Why is this project necessary? Meanwhile in the recent past serious flood events occurred in Europe, European Union (EU) member countries have been working on the implementation of the Water Framework Directive \& Flood Directive [2]. Huge infrastructural investments are and will be running. There is a need for i) proper understanding of river system and landscape behavior, possible prevention and measures, how to deal with potential damages and losses; ii) having engineers skilled in the field related to development of water management infrastructure as well as in system operation, who are familiar also with the newest technological achievements, capable to develop area-adjusted solutions by understanding the national/country specific environmental processes. Flood risk management plan is a communicator and disseminator tool of the knowledge gained during two previous stages across the horizontal structures of governmental and non-governmental bodies dealing with flood protection, flood mitigation and flood struggle in general. They mainly include proposals on how to reduce the losses of lives, property and environmental through flood prevention, protection of vulnerable areas and increased flood preparedness in each river basin. Future development plans of regions and cities will get a proper guidance and platforms for future feasibility studies. In Romania, each state institution wants to improve the skills of their employees. There is a lack of specialists who has enough knowledge about the hydro informatics, thus in everyday work there is a very-very limited use of such tool, and meanwhile the work with complex problems has generated recently a need to use valuable tool and proper training series and consultation center. That is in the practice realizable only by means of Lifelong Learning Programs in accordance with the European Commission's and UNESCO conceptions people at all stages of their lives to take part in stimulating learning experiences, as well as helping to develop the education and training. [2], [3].

\section{AIMS AND OBJECTIVES OF THE PROJECT}

a) Provide newest technical solutions and updated knowledge for the intensified water sector development via transfer of good 'living technology which is already running in different part of the world and was not accessible for the aimed target group due to language barriers and financial capacities. It will be solved by the training activities of skillful trained national trainers;

b) Establish sustainable, reachable `seats 'of vocational lifelong learning center for flood management where adjusted trainings will be available for professionals in all age. National trainings will be ensured by the trained trainers using not only technology but techniques learnt in the first year of project execution; 
c) Introduce a communication tool for target groups and to integrate their needs into training programme by the help of surveys;

d) Improve knowledge for technical solution assessment methods in integrated water/flood management thus to create basis for quality standard measures, improvements;

d) Provide not only theory of hydro-informatics but its application evidences as well: experience of the real application of the presented IT technology and start real on-site discussion by participation of representative of different sectors;

e) Better availability to the European labor market, to contribute to the personal carrier of practicing engineers;

f) Set up a regional `Excellent Network` for applied hydroinformatics for life-long learning, where high quality cooperation between institutions and enterprises providing learning opportunities was established [1].

\section{GENERAL DESCRIPTION OF THE PARTICIPANT ORGANISATIONS IN THE PROJECT}

"POLITECHNICA" University of Timisoara (UPT), Department of Hydrotechnical Engineering - lead partner, is one of the biggest and most well-known technical universities in Romania and in Central and Eastern Europe, as well founded in 1920. Department of Hydrotechnical Engineering, as part of "Politehnica" University of Timisoara, has a Research Center for Modeling, Designing and Behavior Monitoring of the Hydrotechnical Developments. The main research fields of the center are: managing research projects in water engineering, modern technologies and design in water engineering, numerical modeling of flow and pollutants transport processes, land reclamation and improvement, soil science studies and erosion controls, surveying, cadastre etc. UPT - consortium leader, responsible for smooth project management, coordinates partners` activities and provides the necessary basic human and IT infrastructure of the training centre in Timisoara, Romania. The Department is responsible for national level training execution, dissemination of project results in national and international level and to reach national recognition of training courses and to ensure elaboration of project results into post-graduate course.

DHI a.s. Prague - core partner, is an independent, international consulting \& research organization. DHI operates the software product MIKE 11 a top quality modeling software which remains one of the most widely used MIKE by DHI product. MIKE 11 is synonymous with top quality river modeling applicable in field of flooding, navigation, forecasting, water quality, sediment transport. Most of them involve real-time flow and flood forecasting and many of them include institutional and capacity building elements. During the past 25 years DHI has established numerous real-time forecast systems with the aim of supporting decision making for flood management and for operational support to reservoir management. DHI's technologies are well proven and represent state-of-the-art through DHI's dedicated and continuous Research and Development efforts.
Budapest University of Technology and Economics, Department of Hydraulics and Water Resource Engineering core partner, was established 228 years ago. The activities of Department of Hydraulic and Water Resources Engineering cover the fields of education (gradual and post gradual), research and consulting, including up-to-date international technology transfer and cooperation with universities, research institutes abroad. In this field different aspects of design and upgrading of water infrastructures, operation and control of facilities, management and river basin planning, are considered. The department has a number of advanced tools of computer sciences and software. P2 has high reputation, its staff is skilful and well experienced in adult training and computer based information technology in national and international level (e.g. EUROAQUA Erasmus Mundus) as well.

Middle-Danube-valley Water Management Directorate core partner, operates on $8384 \mathrm{~km}^{2}$ territory of Hungary, what covers the areas of Budapest, Nograd county, $90 \%$ of Pest county and partly the areas of Heves-, Szolnok and BacsKiskun counties. Main tasks: The determination of the water management technical of the establishments, the provision of expert opinions in case of administrative procedures, participating in supervisions, examination of water management complaints, flood and drainage control, preparation of the regional development plans, activities related to the water resource charge for use, participation in the environmental damage compensation and damage prevention procedures.

National Institute for Environment - core partner, operates on $8384 \mathrm{~km}^{2}$ of Hungary, what covers the areas of Budapest, Nograd county, $90 \%$ of Pest county and partly the areas of Heves-, Szolnok and Bacs-Kiskun counties.

\section{KNOW-HOW TRANSFER APPROACH}

The know-how transfer to be adapted is based on an interactive and linguistically approaches. The transfer and testing will be made on 2 levels:

i) First to develop the local knowledge basis (trainers and center with facilities) / this first target group will be the responsible for transferring and adapting the technology into local level. Fully understanding of the know-how and way to transfer further are essential therefore continuous quality assurance \& mutual discussions must ensure the optimal effectivity. The training-series will be implemented into two steps: first 3 course events will ensure the hand over the basis of DHI technology, then it follows by the so called on-job trainings, the exercise based educational modules. Each event provides also opportunity to share and obtain DHI teaching experiences.

ii) 2nd level of testing (= localization) is based on the national adaptation (training materials will be developed in national languages which will incorporate actual local needs based on survey results), the training (and quality form feedbacks) will be for end-users (practicing engineering).

To see and understand better the learnt things, real time application trips are planned (the first for the future trainers 
when they do attend training course in Prague and the second for practicing professionals who followed already any of the national trainings in Romania or in Hungary in the second year of the project) [1].

\section{DESCRIPTION OF MIKE 11}

MIKE 11 is the software product, which made 'MIKE' the brand name for top quality modeling software from DHI and remains one of the most widely used MIKE by DHI product. MIKE 11 is synonymous with top quality river modeling covering more application areas than any other river modeling package available. MIKE 11 is applicable in field of flooding, navigation, forecasting, water quality, sediment transport, or a combination of these or other aspects of river engineering. Extending the range of applications, MIKE 11 also includes options for investigating riverbank overflow and catchment hydrology [4].

MIKE 11 is accepted by US Federal Emergency Management Agency (FEMA) for use in the National Flood Insurance Program (NFIP) [3].

Typical MIKE 11 applications:

- Flood analysis and flood alleviation design studies

- Real time flood forecasting

- Dam break analysis

- Optimization of reservoir and channel gate / structure operations

- Ecological and water quality assessments in rivers and wetlands

- Sediment transport and river morphology studies

- Salinity intrusion in rivers and estuaries

- Wetland restoration studies.

MIKE 11 offers the following hydraulic and hydrological simulation engines:

\section{HD - Hydrodynamics}

DHI's classic 1D hydrodynamic engine for rivers and open channels, robustness and features, including:

- Fully dynamic solution to the complete nonlinear St. Venant equations for open-channel flow

- Muskingum and Muskingum-Cunge routing method options for simplified channel routing

- Automatic adaptation to subcritical and supercritical flow

- A large suite of standard hydraulic structures such as weirs, culverts, bridges, pumps, etc.

- Choice of fixed, tabulated/ adaptive simulation time step.

\section{RR - Rainfall-Runoff}

RR includes a variety of RR-models. Amongst these is a lumped, conceptual and continuous hydrological model as well as the standard unit hydrograph SCS method.

\section{SO - Structure Operation}

SO simulates operational structures such as sluices, overflow and radial gates as well as pumps and reservoir releases from user-defined operating strategies.

\section{DB - Dam Break}

DB provides facilities for definition of dam geometry, breach development in time and space as well as failure mode and includes DAMBRK / FLDWAV compatibility switch.

\section{AUTOCAL- Automatic Calibration}

It is an automatic calibration process for a wide range of parameters, including RR parameters, Manning numbers, head loss coefficients, WQ parameters.

\section{FF - Flood Forecasting}

FF refers to the modeling of real time flood forecasting including state updating and data assimilation features.

\section{ST / GST - Noncohesive Sediment}

This refers to transport, erosion and deposition of uniform and graded noncohesive sediments, including morphological changes on river bed topography.

\section{$A D$ - Advection-Dispersion}

AD include transport and spreading of conservative pollutants and constituents with linear decay (including heat).

\section{ACS - Cohesive Sediment}

This module allows the modeling of cohesive sediment with 3-layer bed description, including quasi-2D erosion.

\section{GIS- Extension}

This is a powerful extension for Arc-GIS providing features for catchment/river delineation, cross-section and Dem data, pollution load estimates, flood visualization/ animation as 2D maps and data/result presentation and analysis [4].

Note.

It is to mention that in urban area the 1D- M11 modeling not enough exactly and 2D models represents a better approach of the physical phenomena. They consider the topographical variations of the terrain and roughness while calculating the depths and velocities in two directions [5]. In the future editions of the training program the $2 \mathrm{D}$ modeling technique will be presented as well.

\section{RESULTS OBTAINED IN THE PROJECT}

The most significant results obtained so far in the project can be summarized as follows:

(i) Establishment of training centers at "Politechnica" University of Timisoara (UPT) in Romania and at Budapest University of Technology and Economics (BME) Hungary with human and IT infrastructure for flood modeling and flooding forecast;

(ii) Training future Romanian and Hungarian trainers who will hand over the knowledge in national languages and develop educational materials; 
(iii) Effective implementation of three national training courses in hydroinformatic theory and applications for specialists operating in various state units and companies involved in decisions against defence flooding including preparation of regional specific case-study projects (50 participants);

(iv) Establishment of a good framework to extend project results and generate further cooperation actions;

Participants in the training have developed applicationspecific projects for simulating flood wave propagation along a river in the region of the institution where they work Fig.1.
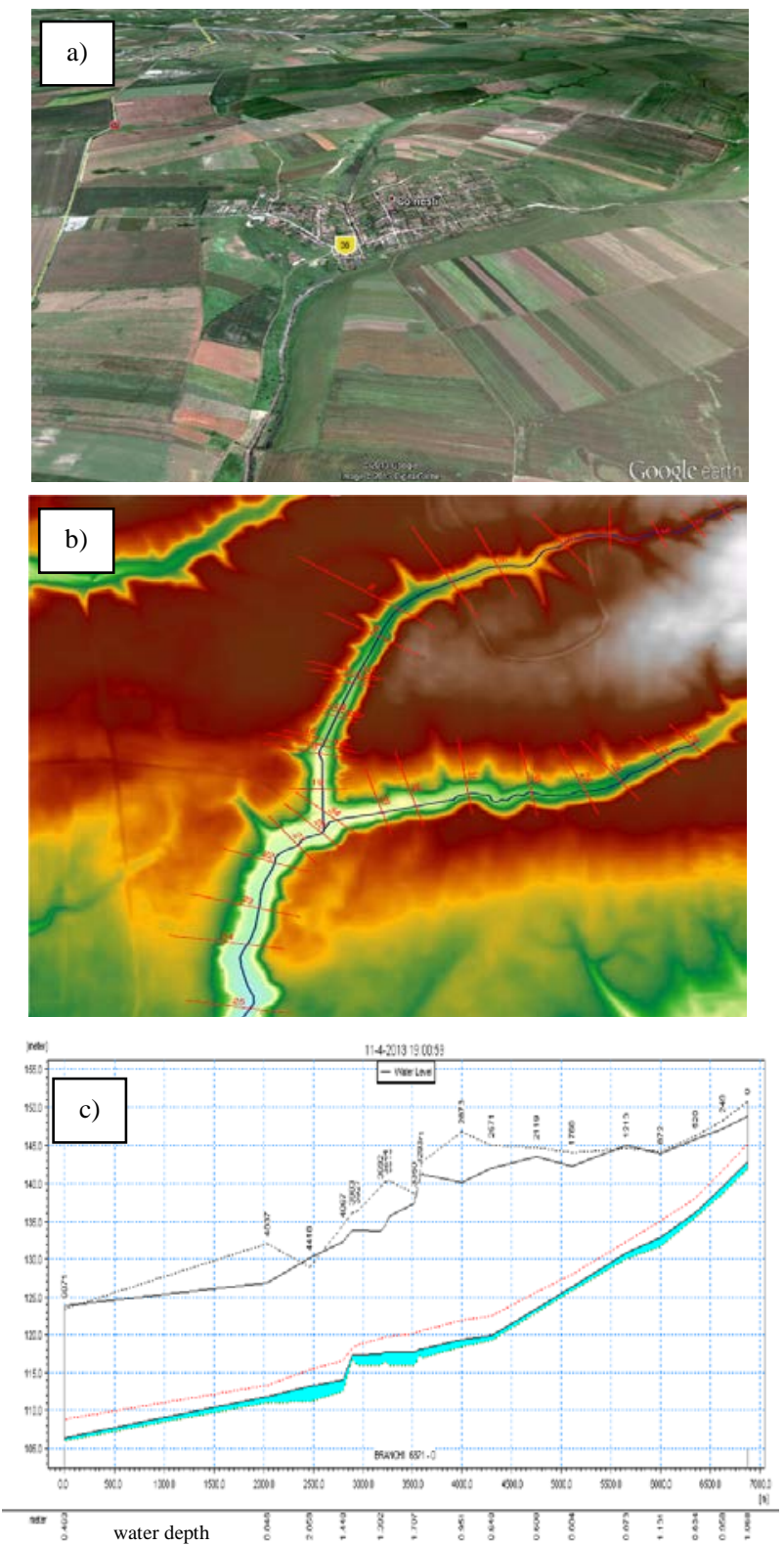

Fig.1 Example for a case study (the river Lac in the town Cornesti in Timis area, Romania):

a) Study area view in Google Earth

b) Numerical model for the river zone (marked cross sections along the river)

c) Longitudinal section along the river with simulated water level

\section{CONCLUSIONS}

As has been mentioned an important concretely outcome of the cooperation project are 2 training centers equipped with computer facilities, educational software, training programme and professional trainers.

That was possible through an excellent project partnership which is formed by two higher educational institutions "Politechnica" University of Timisoara and Budapest University of Technology and Economics (BME), both of them carrying out gradual and post-gradual education, and the DHI a.s. which is the regional office of an independent, international consulting and research non-profit organization of DHI Water, Environment and Health seated in Denmark and a Water Management state bodies represented by Middle Danubevalley Water Directorate and National Institute for Environment, Hungary.

The series of training program of the centers will result a set of specialists countrywide who are able to apply the most updated water management methodologies and tools in their job. This knowledge will enhance their ability to get job not only in the national but also in the European labour market. The impact of the introduction of DHI know-how in the Romanian and Hungarian water management will improve the quality of analyzes and not only forecast of events but consequences of system planning and optimization.

\section{ACKNOWLEDGMENT}

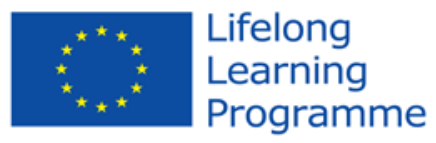

This project has been funded with support from the European Commission. This publication [communication] reflects the views only of the author, and the Commission cannot be held responsible for any use which may be made of the information contained therein.

\section{REFERENCES}

[1] [1] I. David, Zs. Nagy, E. Beilicci, T. Kramer, A. Szilagyi, "Development of knowledge centers for life-long learning by involving of specialists and decision makers in flood risk management using advanced hydroinformatic tools”, Lifelong Learning Programme Leonardo da Vinci, Submission ID 260243, Submission local date (Brussels), 2011-02-28, Hash code 5BA440F7658CABFE, Form id. 5BA440F7

[2] Directive 2007/60/EC of the European Parliament and of the Council of 23 October $\mathbf{2 0 0 7}$ on the assessment and management of flood risks

[3] J. Yang, R. Valdes, “Conceptual evolution and policy developments in lifelong learning", UNESCO Institute for Lifelong Learning, 2011, http://unesdoc.unesco.org/images/0019/001920/192081E.pdf

[4] DHI, MIKE 11 - A modelling system for rivers and channels, Short introduction and tutorial, Horsholm, Denmark, 2011

[5] A. Ghitescu, I. David, An Investigation of Preferntial Flow Path in Case of Urban Flooding Using 2D Mathematical and Hydrodynamical Modeling. Proceedings of the 12th WSEAS International Conference MACMESE '10, University of Algarve, Faro, Portugal, November 3-5, 2010, pg. 281-287,ISBN: 978-960-474-243-1

\section{Creative Commons Attribution License 4.0 (Attribution 4.0 International, CC BY 4.0)}

This article is published under the terms of the Creative Commons Attribution License 4.0

https://creativecommons.org/licenses/by/4.0/deed.en_US 